\title{
Relaciones de traducción: Meister Eckhart y Martin Luther
}

\author{
Marat Ocampo Gutiérrez de Velasco
}

\section{Sobre la traducción}

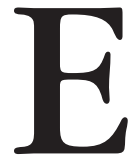

ste texto es una consideración filosófica de la técnica de la traducción. La traducción es un acto político que produce efectos sobre comunidades, produciendo tanto subjetividades como textos.

Hace un par de semanas en un grupo de traducción del texto Situated Knowledges de Donna Haraway tuvimos de visita a Helen Torres, traductora de algunos textos de Haraway al español. Hablamos del problema de traducir cosas como el enunciado de Haraway: "make kin, not babies!" ${ }^{1}$ La palabra kin puede traducirse utilizando Google Translate o tratarse como una unidad separada fácilmente digerible, sin embargo, al sustituirla por parentesco, algo falta. Mientras que esta palabra en inglés refiere a una vinculación con otros asociados que no son forzosamente familia o amigos, en español sus traducciones textuales son poco satisfactorias. La experiencia de traducir al español la palabra kin tiene una reserva que no se puede enunciar con precisión. La traducción tiene que dirigirse a una consideración performativa en que el efecto del llamado a no hacer bebés y hacer $k i n$ se vuelque a la práctica de como pensamos la vinculación comunitaria en este idioma. ¿Cómo hay kin en español? El acto de traducción reta no sólo lo que entendemos, sino cómo usamos eso para relacionarnos.

Al final de esa reunión me quedé dándole vueltas a dos preguntas que resuenan en este texto: ¿Qué vale la pena traducir? ¿Qué efectos tienen las traducciones sobre la comunidad? Por las mismas fechas, me encontré con una nota sobre el fallecimiento del traductor del inglés al macedonio de

${ }^{1}$ Donna Haraway, "Anthropocene, Capitalocene, Plantationocene, Chthulucene: Making Kin", en Environmental Humanities, vol. 6, 2015, p. 161, en http://www.environmentalhumanities.org/arch/vol6/6.7.pdf. [Consulta: 7 de octubre de 2017.] 
Moby Dick, Ognen Čemerski. ${ }^{2}$ La traducción de Moby Dick al macedonio resultaba un reto porque los macedonios no tienen costa desde hace algunos siglos, y hacer una traducción de una novela llena de términos náuticos y centrada en la experiencia del mar, sin que exista una "jerga de marineros", requería desplazarse a las raíces de las palabras y a las prácticas que usaban en tierra partes parecidas a los de los barcos, jugando con un vocabulario de marineros de agua dulce para producir los efectos sobre un lenguaje que no tiene acceso al mar.

A partir de esto, mi gran preocupación, pensando en Eckhart y en Luther, es ¿qué tendríamos que traducir nosotros? Y, ¿qué retos políticos, discursivos y de posibilidad del lenguaje yacen ante estas traducciones?, ¿qué desvinculaciones y vinculaciones buscamos realizar? y ¿qué comunidades podemos pensar a partir esto?

Al final, me quedé con tres preguntas para escribir este texto: ¿qué vale la pena traducir?, ¿para quién traducir? y ¿qué efectos tiene la traducción?

\section{¿Por qué era un problema hacer teología en una lengua que no fuera latín?}

Las traducciones de la Biblia al alemán entre el siglo XIII y el XVI se encuentran y son parte de transformaciones de la comunidad secular, de la comunidad religiosa, de la configuración política y del lenguaje metafísico. Pero, ¿de qué forma tiene un impacto esta traducción en lo político? ¿Qué es traducido al traducir la Biblia al alemán? ¿De qué se trataban las disputas por la traducción?

La cristiandad utilizaba al latín como parte de su capacidad unificadora. El desarrollo del cristianismo había producido diversos cismas y "mientras que en el este las variaciones del koine habían dividido a la Iglesia griega por el lenguaje, el latín unificaba a la Iglesia romana. Pero, en el siglo XIV, las lenguas vernáculas ganaron poder reconfigurando políticamente a los países, incluso conduciendo a la reubicación del papado a Avignon en 1305. ${ }^{3}$ Esto produjo una serie de transformaciones dentro de la comunidad cristiana reordenando las prácticas de la Iglesia cristiana, ya no a partir del lenguaje, sino de la limitación de la comunidad. Los decretos de Bonifacio VIII en 1298, entre ellos

${ }^{2}$ Filip Stojanovski, "Macedonian 'Moby-Dick' Translator Ognen Čemerski, 42, Was a Meticulous Linguist and Engaged Educator", en Environmental Humanities, vol. 6, 2015, phttps://globalvoices.org/2017/08/30/macedonian-moby-dick-translator-ognencemerski-42-was-a-meticulous-linguist-and-engaged-educator/.

3 Paul Berry, The Latin Language and Christianity. Nueva York, Edwin Mellen, 2004 . 
Periculoso y Glorioso en el Liber Sextus ${ }^{4}$-el primero volvía un requisito para todos los grupos de monjas a ser perpetuamente enclaustradas; el segundo buscaba ordenar las veneraciones y reliquias, también estableció a los primeros cuatro doctores de la Iglesia: Ambrosio, Gregorio, Agustín y Jerónimo-, fueron ordenanzas del conocimiento y la comunidad, reconfigurando la pertenencia al catolicismo. Instituir a cuatro teólogos de cabecera de la Iglesia aceleró una modificación de la tradición de discusión teológica del estudio de la interpretación bíblica y la propuesta de formas de interpretar por un esquema de adecuación a ciertas interpretaciones canónicas. El dogma se institucionalizaba a nivel legal y los detractores se podían ya señalar como un grupo de "otros" incompatibles con la comunidad católica. Michel de Certeau llama a esto un periodo de "la tecnificación de las élites y la marginalización de la mayoría de la población en relación con los códigos de un mundo que ha vivido hasta entonces como un sistema de relaciones. Esos hechos tornan opaca a la sociedad". ${ }^{5}$ Los otros serán reconfigurados en nuevas comunidades por la Inquisición, la condena a la filosofía, las cacerías de brujas, entre otros, produciendo una sociedad que no se integra hacia un objetivo uniforme, como la Iglesia católica lo había pensado hasta entonces.

Podemos pensar que la comunidad estaba disputada entre nuevas comunidades políticas no determinadas, opacas, asociadas en parte por las lenguas vernáculas, que se confrontaban a lo propiamente católico dispuesto por una aceptación de la exclusión de la teología por el uso del latín que reservaba la comunidad con lo divino a una sujeción dogmática cada vez más deontologizada. Certeau piensa que esto es una transformación del mundo en que los significantes y los significados cambian. El corpus verum y el corpus mysticum de la Iglesia se ven invertidos. Lo que antes representaba la verdad en el texto es sustituido por la organización católica, y el cuerpo místico es configurado a partir de la observación más rigurosa de la liturgia.

De Eckhart a Luther se puede trazar una narrativa sobre como esta pérdida e inversión condujo a cambios en la comunidad a partir de la práctica de la teología en lenguas vulgares y la traducción de la Biblia. Eckhart y Luther vivieron con dos siglos de separación en pleno desarrollo y consolidación del territorio turingio y fueron educados en tradiciones diferentes, uno dominico, otro agustino, y las crisis históricas que le tocó vivir a cada uno son distintas. No es lo mismo Friedrich Barbarrosa y la disputa con el papado que terminó por expulsarlos a Avignon; que las disputas de Federico el Sabio y Juan el

${ }^{4} \mathrm{Cf}$. Elizabeth Makowski, Cannon Law and Cloistered Women. Washington, Universidad Católica, 1997, pp. 1-5.

${ }^{5}$ Michel de Certeau, La fábula mística: siglos XVI-XVII. México, Universidad Iberoamericana, 1993, p. 103. 
Constante, la separación de los reformistas y la Iglesia católica. Pero ambos escribieron y tradujeron conocimiento reservado por la Iglesia católica a lenguas vernáculas y sus enseñanzas fueron condenadas, teniendo un impacto en la configuración del alemán y lo que hoy es Alemania.

Cuando Eckhart decidió traducir pasajes de la Biblia utilizó una estrategia dirigida a esa no-comunidad opaca. A partir de realizar sermones hablando con grupos cistercenses o de beguinas haciendo sermones públicos y usando el medio alemán alto. La estrategia apofática de Eckhart abre un vacío que exige una aproximación a los textos. La tarea de vaciar a Dios de Dios, eliminar sus atributos, al igual que los del escucha, buscaba poner a los nuevos oyentes ante una tarea no de "entender", sino de producir su propia relación con el texto. Mientras que Luther amplificó dicho efecto al hacer una traducción integral de la Biblia y distribuirla de forma masificada gracias a la imprenta, conduciendo a la invención de una nueva comunidad a partir de la práctica basada en la aproximación directa al texto, contra la comunidad estratificada diseñada por la Iglesia católica.

\section{¿Para quién traducir?}

Tanto Eckhart como Luther estaban preocupados por la compresión de su traducción. Luther lo enuncia como hablar de tal forma que las personas sepan que les están hablando alemán, las mujeres y los niños, mientras que Eckhart señala que:

Séneca, un maestro pagano dice: de las cosas grandes y elevadas hay que hablar con sentimientos grandes y elevados y con el alma sublime. Dirán también que esas enseñanzas no se deberían decir ni escribir para la gente iletrada. A eso digo: Si no se debe enseñar a la gente iletrada, nunca nadie llegará a ser letrado y en consecuencia nadie sabrá enseñar o escribir. Porque se enseña a los iletrados para que de iletrados se conviertan en letrados. ${ }^{6}$

Ambos señalan que sus traducciones tienen el objetivo de tener una distribución a grupos que no han tenido acceso con anterioridad a los textos. Pero ¿podemos pensar que solamente se trata de una estrategia de difusión de la traducción?

Walter Benjamin comienza su texto La tarea del traductor señalando que:

\footnotetext{
${ }^{6}$ Meister Eckhart, Tratados y sermones. Buenos Aires, Las Cuarenta, 2013, p. 225.
} 
En ninguna parte la atención hacia el receptor resulta fructífera para la comprensión de una obra de arte o una forma artística. No es sólo que toda referencia a un público determinado o a su representante lo desvíe a uno del camino, sino que hasta el concepto de un receptor ideal es nocivo en toda discusión sobre teoría del arte, porque de esas discusiones tan sólo se solicita que partan en general de la existencia y la naturaleza del ser humano. ${ }^{7}$

El texto al que se enfrentaban Luther y Eckhart es un texto sagrado que los obliga a considerar la enunciación de la palabra divina. Y aunque la recepción tiene un lugar importante, su disputa es por cómo se sostiene el texto en la traducción. Para Benjamin, la finalidad de la traducción está "en la expresión de la correlación intrínseca de las lenguas". ${ }^{8}$ Y aunque esa finalidad no puede ser expresada directamente podemos pensar que ya se encuentra en los ejercicios de estos autores.

En el prólogo de la Theologia Germanica Luther señala:

Que tantos como quieran lean este libro y entonces digan si la teología es cosa nueva o vieja entre nosotros: porque este libro no es nuevo. Pero, si dicen como antes lo hacían que sólo somos teólogos alemanes, no lo negaremos. Agradezco a Dios que he escuchado y encontrado a mi Dios en la lengua alemana, ya que ni yo ni ellos lo hemos encontrado en latín, griego o hebreo.?

La disputa de Luther era no sólo por amplificar al público lector de la Biblia, sino una disputa por la posibilidad de hacer teología en su lengua y encontrar a Dios ahí.

Eckhart, aunque no habla directamente de la traducción, en varios de sus sermones explica la problemática de la aproximación al texto.

Dice san Agustín: al principio, la Escritura le sonríe a la gente menuda y atrae al niño, pero, al final, cuando uno quiere ahondar en ella, se burla de los sabios: y nadie tiene la mentalidad tan simple, que no encuentre en ella algo adecuado para él y, por otra parte, nadie es tan sabio que cuando quiere ahondare en ella, no la halle [cada vez] más profunda y con más cosas [ocultas]". ${ }^{10}$

${ }^{7}$ Walter Benjamin, "La tarea del traductor", en Dámaso López García, ed., Teorías de la traducción. Toledo, Universidad de Castilla-La Mancha, 1996, p. 335.

${ }^{8}$ Ibid., p. 338.

${ }^{9}$ Martin Luther, Theologia Germanica. Boston, Draper, 1872, p. Xx.

${ }^{10}$ M. Eckhart, op. cit., p. 643. 
Para Eckhart, el problema de traducir la Biblia recae en los límites que impone intentar hacer un trabajo de exégesis. La tarea del traductor no garantiza un comprensión superior del texto, sino que se trata del acceso a un territorio oscuro que no responde a una expectativa epistemológica. El problema de la traducción conduce a un punto en que al buscar para quién traducir no se pueden establecer objetivos, sino que se tiene que renunciar a conocer quiénes son los receptores. Pero ¿esto conduce a que el traductor renuncia a su intencionalidad? Hacer una traducción es dar cuenta de un acto imposible, traduciendo, asumiendo un acto sin correspondencia. La traducción tiene que renunciar a la intención calculada buscando efectos.

Eckhart permite ver esta suspensión de la intención en sus sermones. Se ha sugerido que Eckhart buscó producir efectos performativos sobre su audiencia, recurriendo a maniobras discursivas constituidas como tropos que barrenaban la estabilidad del texto. Por ejemplo, al inicio del sermón Surrexit Autem Saulus..., se traduce el pasaje bíblico de la conversión de san Pablo cuando cae de su caballo y se dice "Se levantó solo Saulo de la tierra, con los ojos abiertos y nada veía". ${ }^{11}$ Para Eckhart esto se desglosa en variaciones aporéticas:

Me parece que esta palabra tiene cuatro sentidos. Un sentido es éste: cuando se levantó del suelo, con los ojos abiertos, nada veía y esa nada era Dios; puesto que cuando ve a Dios, lo llama una nada. El segundo sentido es: al levantarse, allí no veía nada sino a Dios. El tercero: en todas las cosas nada veía sino a Dios. El cuarto: al ver a Dios veía todas las cosas como una nada. ${ }^{12}$

Esta técnica retórica produce un efecto que conduce a suspender la interpretación en el acto de traducción. Aglutinar los sentidos ejerce una fuerza en contrasentido a la determinación de una interpretación dogmática. El trabajo que realiza Eckhart es una tarea en que la búsqueda de la traducción disputa la unicidad de la interpretación. De cierta forma, la traducción actúa contra el deseo de la Iglesia católica de establecer un grupo canónico de pensadores.

Sabemos que esta discusión se encuentra también en Luther como un problema político, ya visible en el Salterio alemán: "Para establecer su doctrina, inventaron sus distinciones que nos intentan forzar a aceptar; diciendo que los sacramentos y las ordenanzas tienen cierto efecto sobre la gracia en nosotros, como la autoridad y poder de Dios" 13 y esto genera dudas sobre la fe. Y para

${ }^{11}$ M. Eckhart, El fruto de la nada y otros escritos. Madrid, Siruela, 1999, p. 87.

${ }^{12}$ Idem.

${ }^{13}$ M. Luther, op. cit., p. XXII. 
Luther es una herejía enseñar que dudar es una sensación divina, esto va contra la fe. La producción de la duda en sí para forzar la adecuación a interpretación dogmática va contra el acto de fe. Tanto para Eckhart como para Luther la problemática de enunciar pensando en la fe es parte de la tarea de pensar en la traducción. La traducción corresponde a una tarea de confrontación contra una búsqueda de convencimiento sobre la estabilidad de las interpretaciones bíblicas hechas desde el latín.

\section{¿Qué traducir entonces?}

Las traducciones de la Biblia de Eckhart y Luther buscaban trasladar algo de las interpretaciones a los actos de enunciación. Actos que se encontraban ya en una comunidad en crisis y sin una configuración determinada. Se trataba de un desplazamiento que exigía abandonar un locus preciso por la posibilidad productiva de la apertura. Pero, ¿qué es esto que se buscaba trasladar o desplazar de la Biblia al alemán?

Podría pensarse que bastaría con suponer que es un acto político de poder que buscaba apropiar o dominar a partir de la apropiación de un texto sagrado. Pero, en realidad, es algo más sutil que une a la traducción con las modalidades discursivas que la transmiten. Franz Rosenzweig pone atención a como la tarea de traducción buscaba acercar a los alemanes al texto original, "a veces atenerse a las palabras, a veces dar sólo su sentido". ${ }^{14}$ Luther malabareaba con las ansias de literalidad y la producción de sentido, movimiento del lector al texto y del texto al lector:

Lutero tenía en la "analogía de la fe" una infalible vara de rabdomante que lo guiaba sin vacilación hacia todos aquellos sitios que en el Antiguo Testamento "impulsaban a Cristo", lo promovían. Ahí donde para él como cristiano estaba la palabra viva de Dios, ahí y sólo ahí, pero sin condicionamientos, debía ser tomada literalmente y por tanto también traducida con "rígida fidelidad". ${ }^{15}$

Esto tendríamos que pensarlo a partir de la estructura de la enunciación. Cuando hablamos de enunciación se trata de pensar la enunciación del verbo. Impulsar a Cristo es enfatizar los pasajes que refieren al acto creativo a partir de la enunciación. Lo que Luther hace está relacionado con buscar la litera-

${ }^{14}$ Franz Rosenzweig, Lo humano, lo divino, lo mundano. Buenos Aires, Limod, 2007, p. 345.

${ }^{15}$ Ibid., p. 346. 
lidad cuando se anuncia el proceso de enunciación más que la anticipación de la figura de Cristo. La traducción redispone los materiales para facultar la aparición de mecanismos metafísicos en el lenguaje.

Eckhart aborda esta cuestión cuando señala: "San Agustín dice que quien comprende mejor la escritura es aquel que, desprendido de todo espíritu, busca el sentido y la verdad de la Escritura en ella misma, es decir, en el espíritu en el cual está escrita y pronunciada, es decir, el espíritu de Dios". ${ }^{16}$ Esta postura que se diferencia de la aproximación a los textos deontológicamente, anticipa que el espíritu y la capacidad de la compresión está en insistir en el espíritu de Dios. Para Eckhart, esta posición está relacionada con el acto de creación a partir del verbo. Para él la tarea inminente de la práctica religiosa es la eliminación de las atribuciones divinas. Ningún atributo corresponde a la naturaleza divina. La aproximación a lo divino tiene que partir de un vaciamiento que implica la posibilidad de posicionarse en el acto creativo. Lo que tiene que ser traducido no es algo específico.

Luther considera, en el comentario al segundo salmo, que "nuestra traducción de este pasaje, por lo tanto, no difiere del hebreo en su sentido. Y, aunque una diversidad en la lectura hará a veces una diferencia en el sentido, mientras la misma verdad sea asida, la diversidad en la lectura no perjudicará, por lo tanto no quiero se contencioso". ${ }^{17}$ No busca tener una disputa por la precisión de una traducción específica, sino que busca algo que no puede ser particularizado ni por la interpretación, ni por la correspondencia literal del texto. Para Lutero, una traducción completamente literal de la Biblia sería incomprensible. Pero, al mismo tiempo expone un problema, ¿cómo diferentes lecturas logran asir una misma verdad? Esto tiene que ver con una modificación de la noción de verdad en esta época.

Lo que está en juego en el acto de traducción de la Biblia es la posibilidad del lenguaje. Benjamin termina su texto La tarea del traductor hablando del abismo del lenguaje que permite hacer guiños entre distintos lenguajes es disputado por el texto sagrado que llama al decir verdadero en conexión con el texto.

Ante él se exige de la traducción una confianza tan ilimitada que la literalidad y la libertad tienen que unirse en ella, sin tensión alguna, tal como la lengua y la revelación en aquel, y eso en forma de la versión interlineal, pues en algún grado todas las grandes obras, pero en el más alto las sagradas, comprenden entre líneas su traducción virtual.

${ }^{16}$ M. Eckhart, Tratados y sermones, p. 205.

${ }^{17} \mathrm{M}$. Luther, Commentary on the First Twenty-Two Psalms. Minneapolis, Lutherans in All Lands, 1903, p. 81. 
La versión interlineal del texto sagrado es el arquetipo o ideal de toda traducción. ${ }^{18}$

¿Qué quiere decir Benjamin con esto? El arquetipo o ideal de toda traducción, una forma en que el interlineado, muchas veces descrito como una disputa continua entre la traducción virtual que se sostiene a partir de su medio, sea un lenguaje, un libro, un $e b o o k$, una servilleta que se contraponen con aquello que es expresado, tiene que ver de alguna forma con la tensión entre el texto sostenido y sosteniendo el lenguaje. Tiene que ver con el proceso de producción del texto y la traducción inventando el lenguaje. ¿Cómo pensar la interlinealidad de la traducción?

La traducción del texto no es un ejercicio de equivalencias entre un lenguaje y otro, sino una suma de procesos entre las posibilidades del texto, el medio y las del lenguaje. De cierta forma, en la traducción al alemán de la Biblia, trasladaron las capacidades metafísicas al lenguaje vernáculo y sus hablantes, dotando de nuevo a la Biblia de una posición constitutiva en la comunidad a partir de ejercicios sermonísticos y la imprenta. Se permitió a nuevos grupos participar en los procesos de la metafísica cristiana. Ya no era sólo una tarea para las comunidades que sabían latín. Pero, la estrategia no sólo conducía a eso, sino que cambiaba la práctica metafísica. Una práctica metafísica que reestablecía las conexiones entre lo cotidiano y lo divino. Lenguas de todos los días y el texto sagrado.

\section{Conclusiones: ¿qué efectos tiene la traducción?}

Sabemos que Eckhart y Luther ejercieron una influencia formativa en la lengua alemana a partir de la traducción de la Biblia. Y que tuvieron un impacto revolucionario en la secularización a partir de una operación de desbasamiento y aproximación de los textos y los lectores. Rosenzweig dice que "Para la iglesia protestante la traducción de Lutero llegó a ser lo que la Iglesia católica con su amplio sistema institucional ya poseía: el portador de su visibilidad". ${ }^{19}$ No sólo condujo a ser una apropiación del texto, sino que constituye la base de la Iglesia protestante. No ya una institución altamente jerarquizada, sino un texto y una forma de aproximarse a la fe. Por su parte, Amy Hollywood insiste que Eckhart logró un diferimiento y diferenciación en el lenguaje,${ }^{20}$ son una reinvención

${ }^{18}$ W. Benjamin, "La tarea del traductor", en op. cit., p. 347.

${ }^{19}$ F. Rosenzweig, op. cit., p. 352.

${ }^{20}$ Janet K. Ruffing, Mysticism and Social Transformation. Siracusa, Universidad de Siracusa, 2001, p. 76. 
de la existencia humana. Diferir es parte de la tarea de traducción. Suspender una decisión que produce la posibilidad de un texto. La comunidad se configura con ese diferimiento al mismo tiempo que aproxima a los ejercicios de escucha y examen. De cierta forma las configuraciones comunitarias que se produjeron por el movimiento de Eckhart a Luther podríamos entenderlas a partir de una transformación del lenguaje, la comunidad y los textos abriendo posibilidades de un ejercicio creativo que no se puede magnificar sólo como las posibilidades filosóficas, técnicas y literarias del alemán, sino también como una cierta forma de enunciar a partir de ese lenguaje. Una relación entre especificidades y heterogeneidades que no pueden ser resueltas e igualadas, pero que afectan la forma en que se habla y se escribe.

Tenemos que pensar que la tarea de traducción corresponde a una práctica de resistencia al enclaustramiento y ordenamiento de las prácticas para hacer de la comunidad una reserva para la élite. Y que ejerciendo un tipo de encuentro inestable, ante superficies que se resisten a la apropiación, mediante ejercicios de apropiación productiva que cedan la propiedad del texto, que es como entiendo, provisionalmente, en la traducción hay una posibilidad de transformación. La traducción es una técnica política de apropiación productiva y transitoria. Una técnica que tiene que revelar a partir de su confrontación con el acto de producción/enunciación/creación una posibilidad de comunidad. Pero para que se vuelva efectiva tiene que reconocer y practicar la reserva de su alcance. Tiene que ver con una estrategia de aceptar el oscurecimiento y lo imposible de reservar, mientras sigue enunciando. 